\title{
Doing/Undoing Gender in Research and Innovation - Practicing Downplaying and Doubt
}

\author{
Päivi Korvajärvi ${ }^{1 *}$
}

Published: September 1, 2021

\begin{abstract}
The aim of this article is to analyse the ways in which highly educated women 'do' and 'undo' gender when they reflect on their work and careers in research and innovation (R\&I). The broader research task is to identify the gendering effects that 'doing' and 'undoing' gender achieve in R\&I work. The findings indicate a constant uncertainty among interviewees about whether gender is significant at work. There are few signs of interviewees 'undoing' gender with the aim of changing the status quo. Instead, they conceive of gender as insignificant for various reasons, usually because of an absence of individual experience. They understand the core of gender equality at work in terms of a numerical balance of women and men and the promotion of balance in female-dominated work communities. The argumentation by women in R\&I about 'doing gender' can be defined as 'gender-doubtful'. Interviewees oscillate between two notions of the effects of gender: they see that gender may have an impact, but at the same time they resist any feelings about that impact by deploying counterarguments or scepticism. This article calls for an analysis of the ways in which doing and undoing gender are situationally specific.
\end{abstract}

Keywords: doing gender, undoing gender, research and innovation

\section{INTRODUCTION}

The aim of this article is to identify ways of 'doing gender' expressed by highly educated women working in research and innovation (R\&I). In their ground-breaking article, Candace West and Don Zimmerman (1987: 129) propose that gender is 'the product of social doings of some sort' and 'produced as a socially organized achievement', meaning that people do gender in their social interactions. According to their core idea, gender is 'an ongoing accomplishment' (Fenstermaker and West, 2002: 42) embedded in everyday and routine interactions between people (Fenstermaker and West, 2002: 6). By enabling the analysis of how people practise, recount and convince others about gender matters in their everyday lives, the concept of 'doing gender' aims to open up ways to discern the embeddedness of gendered structures - power relations, hierarchies and differences - in everyday life. Thus, doing gender and its consequences 'are linked to and supported by historical and structural circumstances' (West and Zimmerman, 2009: 117).

The main focuses of 'doing gender' differ according to the conceptual approach adopted. The production of gender in interaction is the focus of ethnomethodological sociology, whereas the production of gender identities and positions through discourse is the focus of the poststructuralist approach (Moloney and Fenstermaker, 2002; Nentwich and Kelan, 2014). Despite their differences, these approaches share an understanding of gender as both a verb and a dynamic process.

Empirical studies on gender in society, and conceptual developments based on such empirical studies, have crossed the borders between these approaches, thereby demonstrating the fluidity and contextuality of gender in society (Nentwich and Kelan, 2014). This is also apparent in a variety of influential feminist contributions whose empirical analyses draw, for example, on gendered processes (Acker, 1990), gendered practices and the practising of gender (Martin, 2003), the mobilisation of masculinities (Martin, 2001) and remedial and ceremonial work (Gherardi, 1995).

The aim of using the concept of 'doing gender' is to reveal persistent gender inequalities and pave the way for alternative and transformative ways of understanding gender. Consequently, in addition to doing gender, the question of undoing gender has become salient. The concept of 'undoing gender' can have different emphases, 
such as the transformation and diminishment of the relevance of gender in the interactionist approach, or the subversion of subject positions in the poststructuralist approach (Nentwich and Kelan, 2014; Butler, 2004). In addition, 'undoing gender' can be understood as referring to conscious activities to make gender irrelevant in society (Deutsch, 2007), 'degendering' through the elimination of gender differences (Lorber, 2005), challenges to the gender binary (Risman, 2009), or the denial of gender at work (Britton, 2017).

In her analysis of women academics in science, technology, engineering and mathematics, Dana Britton (2017) found that such women tended to minimise the significance of gender in their interactions. With regard to structures, although the women recognised gender discrimination, they did not experience it as intentional or systematic; in relation to culture, they felt that gender became visible only randomly. Britton concluded that the women understood gender as an isolated phenomenon at work, and consequently that gender needs to be analysed and placed within organisational contexts. In this article, my aim is to analyse how women reflect on gender in R\&I work. I argue that doing and undoing gender affects and mobilises women in ways that may have both advantageous and disadvantageous gendering consequences at work and in organisations.

My analysis takes place in the context of Finland, a country with a favourable reputation for gender equality (Kantola et al., 2020). This means that the assumed prevalence of gender equality is often taken for granted, both in research and among the public. However, statistics demonstrate the clearly gendered segregation of educational sectors, occupations and industries, as well as hierarchical inequalities and a wage gap in organisations (Gender Equality in Finland, 2018). Engineering, manufacturing, construction, and information and communication technology (ICT) are male-dominated, while the arts, humanities and social sciences are female-dominated (Gender Equality in Finland, 2018). Patented innovations are mostly registered to men, thus strengthening the gendered segregation of R\&I. Moreover, men's patents are typically related to highly advanced technology, whereas women's patents are related to what are regarded as less-developed technologies. Women work and produce innovations mostly in the pharmaceutical and chemical industries, whereas men's work involves developing machines and related equipment (Poutanen and Kovalainen, 2017: 21). Qualitative studies have also reported the undermining of and discrimination against women in academia - a core site of R\&I work (Husu, 2001; Kantola, 2008).

In addition, it is important to consider how gender matters are recognised and valued in society. Women's and men's views on gender equality in working life differ strongly; women report far more experiences of harm than men (Attila et al., 2018: 67-70). However, the general attitude in Finland is that everything regarding gender equality and equal opportunities is good compared with many other countries in Europe. A few years ago as many as 70 per cent of women believed that gender equality strongly or very strongly prevailed in their workplace; among men, the rate was even higher (Attila et al., 2018: 63-64). This pride in being 'more advanced' than other countries results in the disregard of gender issues. Gender equality is a contested (Elomäki et al., 2019) and highly emotional issue when it comes to its promotion in the workplace (Ylöstalo, 2019). The late 2010s saw a weakening of equality policies, both within the Finnish government and in the European Union (EU) more widely. Situational and project-type feminist activities have recently taken up more space in the Finnish political arena (Elomäki et al., 2019). However, active feminist politics around R\&I in Finland is sparse; where such politics does exist, it is very local, individually based or informal, and is only on its way to becoming visible. In short, the culture in Finland is highly complex and contradictory: clearly gendered segregation and power relations coexist with a strong belief in the prevalence of gender equality.

In the next section, I continue my theoretical considerations of doing and undoing gender, before moving on to outline the research interviews and method of analysis used in this paper. I suggest that the argumentation about doing gender by women in R\&I can be defined as 'gender-sceptical' or 'gender-suspicious'. Our interviewees were unsure whether gender had any effect on them or their organisations. They oscillated between two notions of gender effects: they saw that gender had an impact, but they nonetheless presented counterarguments or showed scepticism about it.

\section{COMPLEX DOINGS OF GENDER}

In ethnomethodological approaches, 'doing gender' is often seen as a way to conceptualise conventional and conservative practices, whereas poststructuralist approaches conceptualise 'doing gender' in terms of possibilities for change and transformation (Nentwich and Kelan, 2014; Pecis, 2016). However, the two approaches are not mutually exclusive. They both suggest that research into doing gender should look for structures, hierarchies and gender identities, their flexibility and contextuality, and the strength of gender's relevance in a given social context (Nentwich and Kelan, 2014). Patricia Yancey Martin (2003; 2006) shows in her empirical analysis that the two approaches are intertwined, inseparable and applicable in combination. This means that available gender discourses and ways of practising gender are related to each other.

Empirical analyses suggest that gender is also done by treating or understanding it as non-existent. Doing gender is often identifiable, yet gender is also done silently, or seemingly not done at all. Rosalind Gill (2014) suggests that 
inequalities in creative work are performed and produced by not speaking about inequalities, in such a way that femininities or masculinities do not give meaning to people's activities or their outcomes. In a similar vein, Liisa Husu (2020) proposes that gender can sometimes be done in silence, out of sight and away from recognised incidents. Thus, gender can be done in non-events that are hard to perceive and recognise.

Such silent and invisible ways of doing gender imply that the concepts of 'gender neutrality' and 'gender fatigue' are also worth considering as ways of doing and undoing gender. On the basis of diverse analyses of gendered practices in Finland, it can be concluded that gender neutrality is a common attitude towards gender issues among employees and employers (Rantalaiho and Heiskanen, 1997; Korvajärvi, 2011). This means that gender inequalities are recognised but simultaneously repudiated, because the general model of thinking is that gender equality has been achieved in this country. This is also referred to as the 'duality of gender': impressions of both gender inequality and gender equality are simultaneously felt to be reliable and true (Benschop and Doorewaard, 1998). International comparisons and publicity about Finland (e.g. Kale, 2020) confirm this when they celebrate the achievement of equality. Although they recognise gender conflicts, people prefer to regard their own society or organisation as providing equal opportunities to both women and men.

This is close to how 'gender fatigue' works as a thought model. This concept, suggested by Elisabeth Kelan (2009), also helps us to understand how appearing not to do gender is itself a way of 'doing gender'. Her suggestion is based on an analysis of ideological dilemmas where people use and accept knowledge that includes simultaneously contradictory aspects. Kelan identifies two strategies that ICT workers use in their argumentations: the temporal displacement of gender conflicts to the past, and the feeling among women that they have to take individual responsibility for changing discriminative practices. In a study of ICT workers in Switzerland, Kelan concludes that with regard to structures the women were 'tired of seeing gender discrimination and prefer[red] to see a world which is gender egalitarian, where gender no longer matters' (Kelan, 2009: 199). I interpret this as an affective stance towards gender, since it mobilises workers to think of gender questions as irrelevant but not nonexistent. Both the irrelevance and the non-existence are emotionally burdensome in that emerging inequalities are surprises and hard to deal with.

The concept of 'undoing gender' can refer to a multiplicity of arguments. One such argument is that gender is becoming irrelevant or ceasing to shape interactive encounters between people (Deutsch, 2007). Accordingly, the relevance of gender vanishes in certain contexts or situations. Another argument, suggested by Kelan (2010: 188), is that doing and undoing gender are very close to each other, since undoing gender 'seems to mean doing gender differently'. For poststructuralist approaches, 'undoing' takes place when discursively produced gendered norms are questioned (McDonald, 2013). Accordingly, normative and stereotypical female characteristics or discourses are found in certain situations, such as when men care for other people, or when women work in male-dominated fields such as R\&I.

Analyses of doing gender and its variations show that gender is far from non-existent in R\&I work. Indeed, it is crucially embedded there. Lara Pecis (2016) emphasises that the practices of doing gender in innovation processes are ambiguous and messy. Thus, it is not always clear when gender is an integral part of everyday innovation work or organisations. Pecis (2016) introduces the concept 'positions of displacement': at the core of doing gender is its constant fluidity, which suggests the erosion of a preconceived binary gender order. Accordingly, femininities and masculinities interact with each other, and are mobile rather than strictly identifiable entities. Moreover, her findings indicate that gender orders in innovative organisations can be unexpected, and that the binary order can be undone.

In short, the doing and undoing of gender in society have a multiplicity of conceptual dimensions. But 'doing' and 'undoing gender' stress different aspects of gender. Approaches to 'doing gender' aim to reveal gender inequalities and the power of gender's relevance in various social contexts. In addition, 'doing gender' can refer to the invisibility or denial of gender. 'Undoing gender' includes variations such as making gender consciously irrelevant, doing gender differently, and seeking to change gender inequalities. It can also be interpreted as certain ways of 'doing gender', and thus as being on the edge of the same phenomenon. Gender neutrality and gender fatigue can frame the doing and undoing of gender, and express affective stances towards gender, including suspicion, indifference and exhaustion.

This article examines the ways in which women in R\&I do gender in a culture that is imbued with the assumption of prevailing gender equality. The specific aim is to contribute to the discussion by analysing interviewees' argumentation about the insignificance of gender and their resistance to doing gender (e.g. Kelan, 2010; Nash and Moore, 2018). The focus is on the views of women in R\&I who express or justify indifference, denials of gender, or avoidance and hesitancy in relation to the meanings of gender. There are two concrete underlying research questions: what are the ways in which highly educated women working in R\&I reflect on and speak about the (in) significance of gender in their everyday lives at work? What implications do the ways of doing and undoing gender have for gender (in)equalities in R\&I work? On the basis of the empirical analysis, the article 
makes it possible to rethink 'doing gender', advocating a research agenda that looks at how emotions and affects are embedded in the ways of doing and undoing gender at work.

\section{METHODS, DATA AND ANALYSIS}

The research material was collected as part of the larger cooperative Nordic project Nordwit (https://nordwit.com/), the broad aim of which is to analyse women's career opportunities and trajectories in technology-driven R\&I. The Finnish team decided to interview women in R\&I, concentrating on women working in health technology in a broad sense. For economic and logistical reasons, the vast majority of these interviews were conducted in one region with a multidisciplinary university and a relatively lively R\&I enterprise sector.

We selected the women by using the websites of the university and enterprises related to health technology. In addition, at the end of each interview we asked for relevant further contacts, thus also using the snowball method of recruitment. We aimed to have women in different kinds of organisational and professional positions, different sectors of the economy, and different research fields. We also aimed to interview women of diverse ages, family situations and origins.

Ultimately, 30 women working in R\&I were interviewed. All were white, and all except two were of Finnish origin. Thus, we failed to achieve the diversity we desired in terms of origin. The ages of the interviewees ranged from 25 to 62 years. The largest age group comprised women aged 30 to 39 years (12) who were born in the 1980s. We had similar-sized groups of women aged 50-58, born in the 1960s (seven interviews), and aged 40-48, born in 1970s (nine interviews). One interviewee was born in the 1950s, and one in the 1990s. Nearly all were heterosexually married (two were divorced), and all but three had children. Two women were single mothers at the time of the interviews.

All but two had $\mathrm{PhD}$ degrees, most commonly in the bio or health sciences or technology. Their doctoral studies and theses usually represented newly emerging (at the time) multi- or interdisciplinary research areas. Three interviewees had $\mathrm{PhDs}$ in established disciplines in the humanities or social sciences, although their research and jobs had also broken conventional disciplinary boundaries.

Slightly over half (17) of the interviewees worked in universities, including one who worked in an applied university. The vast majority of these had successful careers as full or associate professors (five) or senior researchers (seven). In addition to the university staff, three researchers worked in a sectoral research institute, which seeks research funding from the same external sources as universities (EU sources, for example). Six interviewees worked as experts in the Finnish offices of relatively large international firms. Two had jobs in nongovernmental organisations, and two held managerial positions in small Finnish firms. Except for the full and associate professors, those who worked in universities had temporary contracts, as is generally the case in Finland.

In short, there was diversity among the interviewees in terms of their ages, employers, and types of job contract at the time of the interviews. In terms of their personal relationships, family situations and nationalities or ethnic backgrounds, the snowball method produced a homogenous group of interviewees. For all but a few, their educational level was clearly higher than that of their parents. Even though the women were highly educated and worked in a strategic field, they did not represent elite positions in Finnish society. Nearly all of them were familiar with job precarity, since they had worked for at least some time in academia. Their salaries were higher than average but did not make them rich or provide them with a particular status. The interviewees can thus be categorised as highly educated and relatively well-to-do middle-class women who mostly lived with a partner and/or a child or children.

The interviews were conducted between April 2018 and April 2020. Interview agreements were signed according to the EU's General Data Protection Regulation. The interviews were conducted face-to-face in Finnish by team members and colleagues, except for the final interview, which was conducted in April 2020 via Skype due to COVID-19 restrictions. The interviews lasted around one to two hours and were audio-recorded. The verbatim transcription was carried out by a firm that had signed the required confidentiality agreement.

The interviewees were told that the interviews dealt with women's careers. The topics included significant events during their educational and work careers, their current work situations, their future work plans, the effects of gender on their work, and aspects of their work-life balance. If the interviewee did not speak about gender, the interviewer asked about it in relation to various topics. Interviewers rarely interrupted interviewees' speech; rather, the interviewees were allowed to talk about their experiences freely.

As a member of the research group, I participated in the planning of the interviews, including whom to interview and what topics to introduce. However, I was not able to conduct the interviews. Consequently, I mostly had to rely on the textual material. However, as a feminist, I must admit that when analysing and contemplating the content of the interviews, I sometimes felt both anger and puzzlement on one hand, and joy on the other.

The search for and analysis of various modes of doing gender resembled a hunt for shadows of the signs and traces of gender, since gender issues did not frequently arise in the interviews unless the interviewer asked gender- 
related questions. Therefore, I read all the interviews carefully several times, and I picked out items that either explicitly concerned aspects of gender or dealt with gender indirectly. This thematically coded subcorpus of research material comprised 60,000 words in Finnish, close to 100 pages in size 11 font. (The excerpts selected are translated into English here). In this phase, it was necessary to go over the interviews in their entirety and look at the contexts where gender was and was not mentioned. Thus, the analysis of the interviews proceeded from theoretically informed categorisations to the more elusive aspects of doing gender. My analysis process resembled - but did not systematically follow - constructivist grounded theory (Charmaz, 2021) in its aim to explain the analysis transparently: going back and forth between the data and the conceptualisations, making continuous comparisons between them, coding the material accordingly, and memo-writing on the analysis-in-progress (Charmaz and Thornberg, 2020).

In the next section, I analyse how the interviewees reflected on the (in)significance of gender.

\section{DOUBTING THE SIGNIFICANCE OF GENDER}

My focus is on the 'messier' and more elusive ways of doing and undoing gender; experiences of open discrimination are beyond the scope of this article. In fact, only three interviewees were sure that they had encountered such open discrimination. The vast majority -24 of the 30 interviewees - said at some point during their interview that they had not experienced gender issues during their doctoral studies or later in their work history. However, this appeared to be far from the whole story: there was wide variation in the ways in which the women ignored or passed over gender issues, and in how certain they were about the unimportance of gender in their work or organisation. Furthermore, what made the situation more complicated was that when talking about the insignificance of gender, the same women would also pick up a different theme - either later in the interview, or simultaneously - that they considered to be more important than gender.

My analysis of the interviews revealed five patterns in the interviewees' reflections on gender or its absence in their everyday lives. I identify these patterns in relation to doing and undoing gender, as follows: 1) doing gender by not doing gender; 2) doing gender by justifying one's doubts; 3) doing gender with reservations; 4) doing gender by speculating and anticipating; 5) undoing gender by dismantling female domination. In addition, following Britton (2017), I looked for the ways in which gender was conceived as isolated or context-bound in R\&I work. Furthermore, I watched for expressions of affect such as doubt, security, pride or insecurity in relation to gender. The overall aim of my analysis is to discuss the implications of ways of doing and undoing gender for gender (in)equalities.

In the following, I quote extensively from 18 of the interviews. The aim is to present the full range of views related to each topic, and to show the complexity of doing or undoing gender as experienced by the interviewees. Therefore, I quote the women whose arguments or thoughts add relevant information about aspects of gender in R\&I work.

\section{DOING GENDER BY NOT DOING GENDER}

There were women who said explicitly that gender issues had not affected them or their work organisation. They connected their views to their personal situations and to what they had not experienced. This meant, according to them, that gender had not been a reality in their work communities or recruitment processes. One sign of the absence of gender was that the interviewees had not experienced anything gender-specific, or - and this was repeated - that they themselves had not felt any discrimination based on gender.

One principal researcher working outside academia felt that she had never experienced or registered that she was the only woman in her organisation. It was a question of adjustment: 'Because it's been like that from the beginning, so I've never really paid attention to it.' A senior researcher working at a university linked the gender question to career opportunities:

I don't know, and I haven't really heard either, that we'd have that, in this unit at least, that gender would have somehow affected your prospects.

The manager of a company connected gender to discrimination, saying:

I don't know (...) or else I'm blind or something, but personally I don't think I've experienced any discrimination.

A professor who cooperated closely with the heads of her organisation was unsure about the role of gender with regard to leadership positions: 
Well, if you think about the leadership of the faculty/organisation, the superior is a man, the vice superiors are men. So maybe, but I don't really know if gender has been the deciding factor there or what the criteria were.

Furthermore, events in which the undervaluing of women was clear appeared to be so rare that it did not make sense to consider them events; rather, they were non-events. When such incidents took place in unusual situations, at a distance from everyday work, they were seen as mere trivial details, as reported by one manager of a small firm:

Shall we say that in some ways yes and in some ways [gender] doesn't affect anything. On the other hand, I personally haven't felt like it has much of an effect on anything. Sometimes in some conferences (...) you do often start to feel like, did that guy call me a girl just now? But when you just let it go and don't get involved, it doesn't matter (...) they're pretty isolated events in the end.

Rosalind Gill and her colleagues (2017) found the same minimisation of potential undermining and discrimination. They suggested that this might be a way for women to cope with their experiences of gender inequality. Thus, denying gender issues appears to be doing gender by adapting to the existing inequality.

In our interviews, a variety of reasons were given that appeared to push gender aside or keep it at bay, denying its significance at work. For interviewees, the individual's personal experience was the criterion according to which gender was irrelevant in their R\&I work. This is also the case among women academics in the United States, as Britton (2017) suggests. However, these denials of the relevance of gender included some reflections about not knowing, not hearing or not paying attention. The women seemed to be uncertain. While they lacked individual experience and expressed individual reasons, gender was also conceived of as a woman/man binary in which men disturbed gender equality, but not to the extent that it made sense to take notice of trivial incidents. Thus, gender was also understood as two collectives comprising women and men.

\section{DOING GENDER BY JUSTIFYING ONE'S DOUBTS}

One way to react to the question of gender was to change the subject to something that interviewees said and felt was more important. At the same time, there was a sense that, in principle, gender was impossible to perceive in the same way as other issues. One expert pondered the meaning of gender for her in relation to personality, although with some uncertainty:

I don't know if it's had an effect, it hasn't hurt at least (...) yeah. Of course, it's probably more a matter of personality.

Similarly, one professor said, 'I don't know if gender does matter as much as personality, maybe.' A co-owner of a firm thought that age was decisive in recruitment:

There hasn't (...) been any direct discrimination or harassment ever, in my opinion. So, it's more like these nuances maybe or how you might experience something yourself. Like, specifically, if I've applied for a job, then I feel like young men, younger men go ahead of me.

A senior researcher spoke about her experience of a troublesome female boss:

[W] hen I started thinking about this, what's had a bigger effect, there are certain personalities and they've been (...) men. But there has been one woman there, too. (...) [W] hen you want to make other people's lives more difficult, that can happen regardless of gender. I don't feel like it [gender] has played a part.

However, passing over gender was not only about people's personal characteristics. Disciplinary battles could outweigh gender, as one senior researcher said of her difficulties in obtaining an appointment in another organisation:

I suspect that it's not so much a matter of gender, but more a kind of battle over science, like what field gets the funding and which one wins.

It is possible to interpret this statement as meaning that a particular discipline might have a gendered image, or even a gender. In addition, this interviewee referred to the multidisciplinarity that she herself advocated and represented, and which she felt was an obstacle for her as a woman. Thus, one's research can have characteristics that may also include a gendered image. This was not explicitly mentioned, but it was an additional aspect in the context of the whole interview. It is well known and self-evident that gender does not have an effect in isolation; 
rather, it functions in various intersections with other personal characteristics or social categories - strongly in some situations, and less so in others (Crenshaw, 1991; Lykke, 2005).

However, according to this pattern, gender was systematically presented as less relevant than other differences between people, although these differences remained vague. I detect here a sense that gender is an elusive and ambiguous matter that is easily taken for granted, or about which scepticism is justifiable. Interviewees seemed to think it was more relevant to mention something more important, thereby making it possible to put gender aside, rather than to do gender differently or aim for change - that is, to undo it. Putting gender aside appeared to include both denying gender and relating it to other things simultaneously. Gender and other issues were expressed in ways that intertwined and entangled them, albeit elusively. Nevertheless, possibly gendered meanings were supressed in favour of other issues - whether structural, such as age or position in the organisational hierarchy, or individual, such as personality.

\section{DOING GENDER WITH RESERVATIONS}

One way of expressing the meaning of gender that came close to finding intersections was to state a fairly clear message but then, almost in the same breath, to express reservations about what had just been said. There were several topics and contexts where such reservations were expressed.

A senior researcher in academia expressed reservations on each occasion in the interview when she spoke about her views on aspects of gender during her doctoral studies. The following quotations show how miscellaneous and contradictory aspects of gender can be. The interviewee recognised that women were not perceived as professionals - as Kelan (2010) has also shown - and spoke about the classic situation of women as coffee makers, but with a remark that this was not an everyday phenomenon. She said that perhaps women were not really appreciated in the way that men were, and that there was possibly a traditional role in which women made coffee - and then she laughed. She also said that while women's organisational competences were appreciated, she thought that everyone, including men, were capable of organising. She continued:

$[\mathrm{M}] \mathrm{e}$, personally, during that time there, I didn't experience that kind of, well, lack of equality, maybe, not directly at least, but I also might be a bit naive. [laughter]

Later she said, 'In our own core group, we didn't have any problems. We got on well regardless of gender.' She was aware of 'shady deals to fill positions', but these did not take place 'in our group, which consisted of half women and half men'. She also noticed the following when vacancies were being filled:

[M]aybe the people who they'd wanted there to start with were men more often than not, but I think, of the ones I've heard, there have been women as well, so it's not always about gender when it comes to who these positions are set up for.

Sexual harassment occurred very seldom according to her, only during 'bar nights' and, she made clear, 'not at work'. Her argumentation followed the same logic - first a statement, and immediately afterwards a qualification - even when she spoke about her husband, who she said 'encouraged' her in everything. However, he did no housework other than what she told him to do.

Reservations were also expressed by another senior researcher, who started by saying that gender questions had not affected her:

I don't think I have thought about [gender] much in this job then. Like, I've come across very little of that, so [gender] hasn't really actualised, so to speak.

However, she continued that gender may have been significant but not explicit:

If I start thinking more closely about why things shape out the way they do, behind it there may be many things that have to do with equality and gender, but they're not so clear somehow.

Thus, gender issues were interpreted as feelings, hesitations, assumptions, non-actualisations, gossip, a good atmosphere and personal character, among other things. These somehow moved or touched people in a way that led them to suspect that the gender issues might not be graspable. That is, gender remained on the informal or shadow side of everyday life. It is as though gender needed supplementation by additional aspects that might make such events and processes relevant at work. 


\section{DOING GENDER BY SPECULATING AND ANTICIPATING}

By speculating and anticipating, the interviewees generated open questions or assumptions about the meaning of gender in their work. Making decisions and recruiting while in leadership positions could be challenging from the point of view of gender. A senior researcher contemplated whether or not gender was a barrier to career advancement. However, it was not easy to admit that gender was a barrier:

[W] hen I was in a leadership position, I do admit that sometimes I wondered if it was about gender when I didn't get in [wasn't invited] to some meeting.

She also speculated as to whether the wage gap was due to women's way of negotiating wages:

[E]ven though they say a woman's euro is different from a man's, you can of course ask whether we women ask for that equal salary. So, it's hard to determine why there are still differences.

She placed women's career options in a context where one might hear something about inequality but in the end had to rely on one's own experience:

But I do feel that in the academic world, there were totally comparable opportunities to advance as a woman. You did sometimes hear that you couldn't get some higher position and someone might say it was because of gender but I haven't come across that.

Another senior researcher who led a large, highly regarded research group and had international funding, was caught between whether women were simply undermined or whether there was genuine discrimination:

[T] he superiors are still all men, so are they really so much more intelligent, or does something happen during your career that somehow diminishes women's personalities and how target-driven we are, or is there actually some kind of discrimination?

She herself had been through a discrimination hearing, at which legal officers had provided evidence. Nonetheless, she hesitated to be definite about the discrimination. In a similar vein, one manager of a firm remembered when her promotion had been delayed:

$[\mathrm{M}] \mathrm{y}$ spouse has pointed out that the recruiting process might have had something to do with gender, which has made me wonder.

Otherwise, however, she held the view that gender had not affected her.

One senior researcher spoke about potential sexual harassment situations:

[A] couple of times, there has been a situation in which an older male professor has made suggestions to me, and I've seen that that's a kind of dangerous situation and that I don't want to be dragged into this. It hasn't been harassment or anything, but I've seen that this, these people have been interested, not necessarily in my research but in something else.

This kind of anticipation seems to depend on past experiences and assumptions regarding whether and when it is wise, for one's safety and bodily autonomy, to step aside and avoid further contact. Unspoken encounters or not-yet-events arouse speculation and anticipation, including hints at gender inequality and gender discrimination, but the women left these inequalities open and elusive. Nonetheless, speculation and anticipation included vague suggestions about existing structural inequalities, such as the gender wage gap or discrimination.

\section{UNDOING GENDER BY DISMANTLING FEMALE DOMINATION}

In addition to the denial of and affective withdrawal from gender matters, the interviewees also talked about how to advance gender equality. Surprisingly, they were concerned about women's numerical domination in relation to the social atmosphere at work and in the outside world. According to the interviewees, the improvement of women's lot would require the recruitment of men and the achievement of mixed-gender or gender-balanced work communities.

This version of the significance of the gender balance was a live issue among women managers or co-owners of small firms. They related the desire for a numerical gender balance to matters of reputation, livelihood, and opportunities to take risks in terms of income and social atmosphere. According to these women, women-only or 
female-dominated organisations might be regarded with suspicion by outsiders. A manager and co-owner of a small firm said:

$[\mathrm{W}] \mathrm{e}$ 've selected the kind of people who have a certain knowhow (...) and they've happened to be women. It's not like we discriminate against men or anything. And as advisors we have tons of men, so that's all fine. But in a certain way we've had to maybe consider whether people will look at us sideways if we hire women, that even if the woman is the better candidate, what it will look like from the outside if we hired another woman, even though it doesn't matter at all to us, because we want to hire the best person. I wouldn't want it to come to that, that it has to matter if it's a man or a woman, but on the other hand how do outsiders see it?

In a similar vein, another manager and co-owner said, 'We're unfortunately really homogenous at the moment. We're all women.' However, she did not regard this fact as entirely negative:

But on the other hand, it's really nice because we're a tech company, so we do have partners who are men.

The interviewees had diverse opinions about and experiences of women's work communities. One line of argumentation presented women's work groups or workplaces as very tough and unpleasant. As one manager, the co-owner of a small firm, said:

[W]omen have some kind of clear need to show off, especially towards each other. (...) I've started, unfortunately, to also feel a bit that women specifically are pretty brutal to each other, and I've even sort of thought we should maybe actually be supporting each other. (...) In work communities where there have been more men, the atmosphere has always been much better to start with. And the more women there are, the more there is this weird kind of backstabbing and needing to show off and somehow actually be really negative like that. It's obviously really unfortunate to say this and as a woman to boot but (...) [t]here's more unnecessary conflict between women, maybe. (...) I'm not saying it's a matter of equality. I mean, I can't say that it's ever been discrimination or anything like that. So, I don't know if it's a matter of equality but personally I do have that experience that a workplace that has more men, I've personally felt, has been more functional.

This view about the bad atmosphere of women's work communities was common. One manager of a publicsector firm wondered why women so often competed with other women. The bad atmosphere in womendominated communities was usually stated as a fact; only one interviewee, who worked as an expert in a big company, said that the bad atmosphere in women's workplaces was a stereotypical way of labelling women's communities. This storyline about women's bad communities has been long-standing among women in Finland and has been found in many studies going back at least to the 1980s (Korvajärvi, 1998; 2002; Koivunen, 2011). However, it is only women who talk about competition, bad atmosphere, conflict and envy in female-dominated workplaces; male bosses do not recognise it, or perhaps will not talk about it to a female researcher (Korvajärvi, 2004).

One university professor was concerned about the numerical domination of female students, and the need to consider

how we can attract male students and maintain the balance (...) to avoid things becoming completely female-dominated.

However, she saw this as a potential opportunity to change the gender composition of the faculty's professors in the future:

[T] he majority are male, but when they retire, women will start to rise up the ladder, so female domination must start to show at some point, surely.

Her belief in the connection between gender equality and equal numbers of women and men was strong, thus following the social and cultural ideal of a structural preference for equal numbers. This included the idea that having a mixture of women and men might pave the way for women to enter higher positions. Her trust in women's future numerical dominance was strong, and according to the interviewee it would give women the chance of a solid career pipeline instead of a leaky pipeline (Blickenstaff, 2005).

The concern about and desire to change women's numerical domination was striking. The interviewees who were concerned about the reputation and image of women working together, or who had experiences of a bad workplace atmosphere, included women working in both academia and business. However, all the women who 
ran small firms were unanimous that women-only constellations did not look good. Consequently, they spoke strongly in favour of and aimed to build mixed-gender workplaces. These interviewees did not clearly say whether they had clients who did not like female-dominated firms, or whether the promotion of business with other firms and the negotiation of funding were more plausible when done by men.

Furthermore, from the point of view of gender as an institution (Martin, 2004), when we include gender orders in each social context, the picture of this undoing of gender expands to relationships between different organisations. The interviews with representatives of small firms suggested that organisations or enterprises preferred not to have exceptional structures or values in their field, following instead the structures and values they saw around them in order to be seen as legitimate and successful. Thus, a normative isomorphism (DiMaggio and Powell, 1983), based on the idea of having the same gendered culture across the R\&I field, may direct ideas about changing and consequently undoing gender in organisations.

\section{DISCUSSION AND CONCLUSIONS}

In this article, I have analysed how women experts employed in R\&I talk about their views of gender at work. My theoretical frame came from broad discussions around 'doing gender', including 'undoing gender'. The data consisted of 30 interviews with highly educated women working in R\&I in Finland. My analysis process resembled - but did not systematically follow - constructivist grounded theory (Charmaz, 2021).

I asked the following questions. First, what are the ways in which highly educated women working in R\&I reflect on and speak about the (in)significance of gender in their everyday lives at work? Second, what implications do the ways of doing and undoing gender have for gender (in)equalities in R\&I work?

The first question relates to the lines of argumentation that are present in the doing and undoing of gender among women experts working in R\&I. I identified four patterns of doing gender and one pattern of undoing gender. The boundaries between these were not clearly delineated.

The four patterns of doing gender included the downplaying of the effects of gender in male-dominated work communities, which allowed the women to think that gender was unimportant. The criterion they used was their own individual experience. This way of doing gender is very much in line with Britton's (2017) finding that women academics tend to deny the significance of gender. Another pattern of doing gender was for the women to be highly doubtful of aspects of the significance of gender. By downplaying it, providing counterexamples, and doubting the truth of the effects of gender, the women came to regard gender as entangled with other issues that were more prominent. Personality or personal characteristics, as well as the prevailing feminine or masculine images of certain issues, were arguments for downplaying gender aspects at work. The women had ongoing reservations about both the significance and insignificance of gender, and while the effects of gender were recognised and regarded as possibilities, the reality of those effects was constantly regarded with doubt. Gender seemed to be in the air, but only as a suspicion. Speculation and even surprise in the face of gender inequalities produced scepticism about whether to believe in their existence. While gender was experienced as elusive, it was understood as a contextual and even structural feature. Furthermore, and due to the uncertainty, gender appeared in R\&I work as almost meaningless on the one hand, but also as potentially very significant on the other. Moreover, the lines of argumentation came close to suggestions of gender fatigue (Kelan, 2009). The interviewees were reluctant to recognise the kind of gender discrimination in which women were subordinated. They preferred to see their working environments as numerically egalitarian. In this respect, their thinking came close to gender neutrality (Korvajärvi, 2011), although our interviewees did not argue that gender equality had been achieved in society.

The pattern of undoing gender by aiming towards change was a surprise - at least for a feminist. The women aimed to give up their numerical domination and create gender-balanced working environments because they felt that a gender balance would benefit the reputation of their organisation, firm, or scientific discipline. The solution was to recruit more men into female-dominated areas, even when there was a woman who was as well or better qualified. However, this solution might ultimately diminish the power of women experts in these firms and might make women's numerical domination - and hence their structural domination - irrelevant. The reason was the fear of a bad reputation resulting from women in exceptional positions. The interviewees spoke of this bad reputation as self-evident, without offering further explanations. Contrary to other patterns of doing gender, this assumption was not an individual one. Instead, it was cultural, framed by implicit gender structures and enterprise cultures.

The argument here is in line with Britton (2017): the women could think that their observations of the insignificance of gender substantiated their view that gender was irrelevant. If their perspective included cultural or structural contexts of gender, or at least hints of them, doing gender was more potentially present. However, cultural and structural contexts were not felt to be clear-cut and salient except in the case of a numerical gender balance (or the lack thereof). In spite of the felt irrelevance of and suspicion towards gender, one thing seemed to be clear: for the interviewees, gender was a binary issue - women and men. There were no signs in the interviews 
of any 'position of displacement' (Pecis, 2016). The gender binary, a strong reliance on the truth of one's own individual experiences, and a simultaneous denial of and suspicion towards existing orders as gendered imbued the interviewees' patterns of doing and undoing gender.

In particular, ways of doing gender were characterised by uncertainty and indifference. The interviewees were not willing to express, or did not know, how gender related to their working lives. If gender aspects were felt to be vague in a given situation, the women expressed scepticism that gender was genuinely present. Certainty about the presence of gender was related to its non-existence on the one hand, and to numerical gender balance on the other.

The second question, regarding the implications of ways of doing and undoing gender for gender (in)equalities in R\&I, relates to gender and affects related to gender (in)equalities. The women were reluctant to speak about the effects of gender at work unless gender was measurable using numbers or their own experience. Otherwise, they felt insecure and hesitant to talk about gender - with the exception of cases of open discrimination, which three of the interviewed had encountered.

Gender was conceived as a potential source of conflict, or as a barrier that would pop up occasionally and prevent women from doing something, particularly from advancing their career in their organisation. The interviewees were successful and had made their way educationally to the top. They were familiar with academia's meritocratic system, which is assumed to be based purely on formal qualifications. Even so the interviewees felt able individually to struggle against inequalities if they suffered personally. In this context, female gender was understood as something negative, entailing feelings of inferiority and insecurity. Talking about gender reawakened feelings that were troublesome and unwanted. However, the interviewees did not tend to position gender inequalities in the past (Gill, Kelan and Scharff, 2017) or at a distance in other workplaces (Korvajärvi, 1998); nor did they blame themselves (Nash and Moore, 2018). Instead, the felt insignificance of gender was tightly bound to the women themselves as individuals who were hesitant to draw on anything other than their own personal experience.

These findings need to be framed with certain limitations concerning first the sample, second the interview method, third the conceptual framework, and fourth the generalisability. First, all interviewees were white women, all but two were of Finnish origin, and a large majority were in heterosexual relationships. Thus, the findings do not include the experiences of non-Finnish women or ethnic minorities, single women, men, or LGBT people working in R\&I. Second, it was my starting point that 'any method' can be deployed to study doing gender (West and Zimmerman, 2009: 116). In this case, the findings about doing gender are based on individual interviews that provided interviewees' reflections on, views of and experiences of gender. Thus, the findings do not directly inform us about actual gendered practices, which would become visible through observations, informal discussions, or other forms of ethnographic fieldwork, or through participative action research. In my view, however, observation would not necessarily address the lack of information about actual practices, since intensive knowledge work such as R\&I can be - and often is - impossible to observe, thanks to its mobility, indefinite working hours and confidential client contact, as well as the mental work it entails (Karjalainen, Niemistö and Hearn, 2015). I consider the quality of the interviews used here to be rich. However, I also consider that a second round of interviews, focusing on the interviewees' uncertainties, reservations, and public opinions, would shed more light on their relationship with gender issues in R\&I work. The views expressed in the interviews discussed in this article reveal more about their overriding and dominant views. Third, existing conceptualisations of 'doing gender' have not explicitly integrated questions of affect. I would suggest that more research and theoretical discussion is needed on the interaction between affects and ways of doing gender. Fourth, the findings do not represent general patterns of doing gender in R\&I work among highly educated women. Instead, the findings reveal a variety of the messy logics of 'doing gender' in R\&I work in the social and cultural context of Finland, which is often assumed to be favourable to gender equality at work.

On the basis of the analysis, I suggest that the interviewees felt undermined but at the same time accepted their situation. They were resigned to celebrating the country's good reputation while simultaneously doubting and downplaying the significance of gender. While the women did not explicitly acknowledge current gender orders, they downplayed gender in the context of their work in R\&I. I think that open discussion about such doubts may move the argument away from individual experiences and towards the cultural and structural orders that maintain constant insecurity. Open reflection on suspicion and indifference may also pave the way for a genuine undoing of gender, that is, a transformation of gender inequalities. The strongly felt egalitarian social atmosphere could provide safe opportunities to share and reflect on this.

This article therefore calls for an analysis of the ways in which doing and undoing gender is situationally specific, and further, the ways in which affects are embedded in the 'socially organized achievements' (West and Zimmerman, 1987) of gender. In addition, and related to my findings, sophisticated further analysis is needed of 'the contemporary common sense on gender' (Kelan, 2018: 106). This entails a thorough analysis of a seemingly dominant gender regime that one might call postfeminist (Utoft, 2020: 126-131, 155), which stresses prevailing assumptions regarding the achievement of gender equality, gender binarity, and the reliance on individual 
experience. This kind of analysis is in debt to both interactionist and discursive approaches of 'doing gender', but needs to reach beyond them into the changing psychic and social situational conditions of doing gender at work (Scharff, 2016). An analysis of the traces of affective views related to doing gender and self-evident assumptions about gender might pave the way for new contributions to tackle gender inequalities in social contexts and societies that maintain a façade of gender equality.

\section{ACKNOWLEDGEMENTS}

I highly appreciate the insightful comments of the anonymous reviewers. I am also grateful to Hanna-Mari Ikonen, Marja Vehviläinen and Oili-Helena Ylijoki for their helpful remarks. Further, my thanks go to Minna Leinonen and Tïna Suopajärvi for conducting the interviews.

\section{REFERENCES}

Acker, J. (1990). Hierarchies, Jobs, Bodies: A Theory of Gendered Organizations. Gender \& Society, 4(2), 139-158. https://doi.org/10.1177/089124390004002002

Attila, H., Pietiläinen, M., Keski-Petäjä, M., Hokka, P. and Nieminen, M. (2018). Tasa-arvobarometri 2017. Sosiaalija terveysministeriön julkaisuja 6/2018. Helsinki: Sosiaali- ja terveysministeriö.

Benschop, Y. and Doorewaard, H. (1998). Six of One and Half a Dozen of the Other: The Gender Subtext of Taylorism and Team-Based Work. Gender, Work \& Organization, 5(1), 5-18. https://doi.org/10.1111/14680432.00042

Blickenstaff, J. C. (2005). Women and Science Careers: Leaky Pipeline or Gender Filter? Gender and Education, 17(4), 369-386. https://doi.org/10.1080/09540250500145072

Britton, D. M. (2017). Beyond the Chilly Climate: The Salience of Gender in Women's Academic Careers. Gender \& Society, 31(1), 5-27. https://doi.org/10.1177/0891243216681494

Butler, J. (2004). Undoing Gender. New York: Routledge. https://doi.org/10.4324/9780203499627

Charmaz, K. (2021). The Genesis, Grounds, and Growth of Constructivist Grounded Theory, in J. M. Morse, P. J. Bowers, K. Charmaz, A. E. Clarke, J. Corbin, C. J. Porr and P. N. Stern (eds), Developing Grounded Theory. New York: Routledge. https://doi.org/10.4324/9781315169170

Charmaz, K. and Thornberg, R. (2020). The Pursuit of Quality in Grounded Theory. Qualitative Research in Psychology, 17(Ahead of Print Article June 2020), 1-23. https:// doi.org/10.1080/14780887.2020.1780357

Crenshaw, K. (1991) Mapping the Margins: Intersectionality, Identity politics, and Violence against Women of Color. Stanford Law Review, 43(6), 1241-1299. https:/ / doi.org/10.2307/1229039

Deutsch, F. (2007). Undoing Gender. Gender \& Society, 21(1), 106-127. https://doi.org/10.1177/0891243206293577

DiMaggio, P. and Powell, W. (1983). The Iron Cage Revisited: Institutional Isomorphism and Collective Rationality in Organizational Fields. American Sociological Review, 48(2), 147-160. https://doi.org/10.2307/2095101

Elomäki, A., Kantola, J., Koivunen, A. and Ylöstalo, H. (2019). Affective Virtuosity: Challenges for Governance Feminism in the Context of the Economic Crisis. Gender, Work \& Organization, 26(2), 822-839. https://doi.org/10.1111/gwao.12313

Fenstermaker, S. and West, C. (2002). 'Doing Difference' Revisited: Problems, Prospects, and the Dialogue in Feminist Theory, in S. Fenstermaker and C. West (eds), Doing Gender, Doing Difference. Inequality, Power and Institutional Change (pp. 205-216). New York: Routledge.

Gender Equality in Finland 2018, Helsinki: Statistics Finland. Available at: http://www.stat.fi/tup/julkaisut/tiedostot/julkaisuluettelo/yyti_gef_201800_2018_19723_net.pdf. (Accessed 2 May 2021).

Gherardi, S. (1995). Gender, Symbolism and Organizational Cultures. London: Sage.

Gill, R. (2014). Unspeakable Inequalities: Post Feminism, Entrepreneurial Subjectivity, and Repudiation of Sexism Among Cultural Workers. Social Politics, 21(4), 509-528. https://doi.org/10.1093/sp/jxu016

Gill, R., Kelan, E. K. and Scharff, C. (2017). A Postfeminist Sensibility at Work. Gender, Work \& Organization, 24(3), 226-244. https://doi.org/10.1111/gwao.12132

Husu, L. (2001). Sexism, Support and Survival in Academia: Academic women and bidden discrimination in Finland. Helsinki: Department of Social Psychology, University of Helsinki.

Husu, L. (2020). What Does Not Happen: Interrogating a Tool for Building a Gender-Sensitive University, in E. Drew and S. Canavan (eds), The Gender-Sensitive University. A contradiction in terms? (pp. 166-175). London: Routledge. https://doi.org/10.4324/9781003001348-13 
Kale, S. (2020). Sanna Marin, The Youngest Female Prime Minister in the World, Talks Sexism, Imposter Syndrome, and Sustainability, Vogue Britain, 31 March. Available at: https://www.vogue.co.uk/arts-andlifestyle/article/sanna-marin-finland-prime-minister-interview. (Accessed 2 May 2021).

Kantola, J. (2008). 'Why do all the Women Disappear?' Gendering Processes in a Political Science Department. Gender, Work \&o Organization, 15(2), 202-225. https://doi.org/10.1111/j.1468-0432.2007.00376.x

Kantola, J., Koskinen Sandberg, P. and Ylöstalo, H. (2020). Tasa-arvopolitiikka muutoksessa, in J. Kantola, P. Koskinen Sandberg and H. Ylöstalo (eds), Tasa-arvopolitiikan suunnanmuutoksia. Talouskriiseistä tasa-arvopolitiikan kriiseibin (pp. 7-30). Helsinki: Gaudeamus.

Karjalainen, M., Niemistö, C. and Hearn, J. (2015). Unpacking the Problem of Research Access(es): The Case of Large Knowledge-Intensive International Consultancies. Qualitative Research in Organizations and Management, 10(3), 274-293. https://doi.org/10.1108/QROM-12-2013-1189

Kelan, E. K. (2009). Gender Fatigue - The Ideological Dilemma of Gender Neutrality and Discrimination in Organisations. Canadian Journal of Administrative Sciences, 26(3), 197-210. https:/ / doi.org/10.1002/ cjas.106

Kelan, E. K. (2010). Gender Logic and (Un)Doing Gender at Work. Gender, Work \& Organization, 17(2), $174-194$. https://doi.org/10.1111/j.1468-0432.2009.00459.x

Kelan, E. K. (2018). Contested Terrain. The Power to Define, Control and Benefit from Gender Equality Efforts, in P. Lewis, Y. Benschop and R. Simpson (eds), Postfeminism and Organization (pp. 105-123). New York: Routledge. https://doi.org/10.4324/9781315450933-6

Koivunen, T. (2011). Gender in Call Centre Work. Tampere: Tampere University Press.

Korvajärvi, P. (1998). Gendering Dynamics in White-Collar Work Organizations. Tampere: University of Tampere.

Korvajärvi, P. (2002). Gender-Neutral Gender and Denial of the Difference, in B. Czarniawska and H. Höpfl (eds), Casting the Other. The production and maintenance of inequalities in work organizations (pp. 119-137). London: Routledge.

Korvajärvi, P. (2004). Tietotekniikan lumoama ja sukupuolen rajoittama palvelutyö, in R. Lavikka (ed.), Sopedu ja vaikuta. Työn tietoistuminen ja sukupuolen pysyyyys (pp. 159-219). Tampere: Tampere University Press.

Korvajärvi, P. (2011). Practicing Gender Neutrality in Organizations, in E. Jeanes, D. Knights and P. Y. Martin (eds), Handbook of Gender, Work and Organization (pp. 231-243). Chichester: Wiley.

Lorber, J. (2005). Breaking the Bowls: Degendering and feminist change. New York: Norton.

Lykke, N. (2005). Nya perspektiv på intersektionalitetet. Kvinnovetenskaplig tidskrift, 26(2-3), 7-17.

Martin, P. Y. (2001). 'Mobilizing Masculinities’: Women’s Experiences of Men at Work. Organization, 8(4), 587-618. https://doi.org/10.1177/135050840184003

Martin, P. Y. (2003). 'Said and Done' versus 'Saying and Doing' - Gendering Practices, Practicing Gender at Work. Gender \& Society, 17(3), 342-366. https:/ / doi.org/10.1177/0891243203017003002

Martin, P. Y. (2004) Gender as a Social Institution. Social Forces, 82(4), 1249-1273. https://doi.org/10.1353/sof.2004.0081

Martin, P. Y. (2006). Practicing Gender at Work: Further Thoughts on Reflexivity. Gender, Work \& Organization, 13(3), 254-276. https:// doi.org/10.1111/j.1468-0432.2006.00307.x

McDonald, J. (2013). Conforming and Resisting Dominant Gender Norms: How Male and Female Nursing Students Do and Undo Gender. Gender, Work \& Organization, 20(5), 561-579. https://doi.org/10.1111/j.14680432.2012.00604.x

Moloney, M. and Fenstermaker, S. (2002). Performance and Accomplishment: Reconciling Feminist Conceptions of Gender, in S. Fenstermaker and C. West (eds), Doing Gender, Doing Difference. Inequality, Power and Institutional Change (pp. 189-204). New York: Routledge.

Nash, M. and Moore, R. (2018). 'I was Completely Oblivious of Gender': An Exploration on How Women in STEMM Navigate Leadership in a Neoliberal, Post-Feminist Context. Journal of Gender Studies, 28(4), 449-461. https://doi.org/10.1080/09589236.2018.1504758

Nentwich, J. and Kelan, E. (2014). Towards a Topology of Doing Gender: An Analysis of Empirical Research and its Challenges. Gender, Work \& Organization, 21(2), 121-134. https:/ / doi.org/10.1111/gwao.12025

Pecis, L. (2016). Doing and Undoing Gender in Innovation: Femininities and Masculinities in Innovation Processes. Human Relations, 69(11), 2117-2140. https:/ / doi.org/10.1177/0018726716634445

Poutanen, S. and Kovalainen, A. (2017). Gender and Innovation in the New Economy. Women, identity and creative work. New York: Palgrave Macmillan. https://doi.org/10.1057/978-1-137-52702-8

Rantalaiho, L. and Heiskanen, T. (1997). Gendered Practices in Working Life. London: Macmillan. https://doi.org/10.1007/978-1-349-25285-5

Risman, B. J. (2009). From Doing to Undoing: Gender as we know it. Gender \& Society, 23(1), 81-84. https://doi.org/10.1177/0891243208326874

Scharff, C. (2016). The Psychic Life of Neoliberalism: Mapping the Contours of Entrepreneurial Subjectivity. Theory, Culture \&o Society, 33(6), 107-122. https://doi.org/10.1177/0263276415590164 
Utoft, E. H. (2020). Motivation, Organizational Gender Equality Work and the Postfeminist Gender Regime: A feminist approach. PhD Thesis. Aarhus: Politica forlaget.

West, C. and Zimmerman, D. (1987). Doing Gender. Gender \& Society, 1(2), 125-151. https://doi.org/10.1177/0891243287001002002

West, C. and Zimmerman, D. (2009). Accounting for Doing Gender. Gender \& Society 23(1), 112-122. https://doi.org/10.1177/0891243208326529

Ylöstalo, H. (2019). Mitä tasa-arvoasenteet kertovat tasa-arvosta?, in M. Teräsaho and J. Närvi, (eds), Näkökulmia sukupuolten tasa-arvoon. Analyyseja tasa-arvobarometrista 2017 (pp. 17-31). Helsinki: Terveyden ja hyvinvoinnin laitos \& Sosiaali- ja terveysministeriö.

Citation: Korvajärvi, P. (2021). Doing/Undoing Gender in Research and Innovation - Practicing Downplaying and Doubt. Feminist Encounters: A Journal of Critical Studies in Culture and Politics, 5(2), 27. https://doi.org/10.20897/femenc/11164

Copyright (C) 2021 by Author/s and Licensed by Lectito BV, Netherlands. This is an open access article distributed under the Creative Commons Attribution License which permits unrestricted use, distribution, and reproduction in any medium, provided the original work is properly cited. 